\title{
CLINICAL TEACHING A CHALLENGING TASK
}

PROFESSOR MD. MARGUB HOSSAIN

Professor of Surgery, Dhaka Medical College Hospital

J Dhaka Med Coll. 2008; 17(2) : 54-55.

Development of competence remains the focus of both graduate and post-graduate medical courses. Clinical teaching that is, teaching and learning focused on, and usually directly involving, patients and their problems lies at the heart of medical education. ${ }^{1}$ For majority courses this is clinical competence and for others it is clinical application of the specialized knowledge and technique. Hospitals attached to medical colleges and specialized institutions are the places that serves dual function of patient service as well as developing clinical competence to juniors .

Hospitals provide immense opportunity to learn clinical skills as there is high influx of patients of diverse pattern and degree of complexity. Medical teachers are responsible for care and service to these patients and also teaching and training of learners. Perhaps the most intense assignment clinical teachers are asked to assume is one or more of a master, mentor, supervisor, and facilitator of learning.

Clinical teaching-learning activities encompass learning of factual knowledge, along with physical examination skills, communication skills, interpretation of laboratory data, problem solving and many others. Application, analysis, and synthesis are the main learning objectives for health science students on clinical rotations.

There are six major tasks required of clinical teachers: a) Preparing the work environment b) Orienting learner what is expected of them c) Facilitating learners developing the thinking skills of physicians d) Facilitating learners ability to act like physicians e) Assessing learners progress in becoming physicians f) Assessing your effectiveness as a clinical teacher. ${ }^{2}$
Emphasis and concern are there on the need for clinical competence and interpersonal skills. The only site in all of medical institutions where such skills can be demonstrated is clinical rounds and teaching at the bedside. It would be intuitively likely that such central parts of a physician's craft as the illumination of history, the integration of history, physical, and laboratory results, and the therapeutic interpersonal skills of a physician would be more effectively transmitted by demonstration during ward rounds than by lecture. The farther away from the bedside we go, the less opportunity our students have to observe experienced clinicians exercising their skills in the diagnostic and therapeutic relationship with patients. ${ }^{3}$ Though patients accept bedside teaching and discussion, too little time is spent by clinical educators at bedside ${ }^{4}$. We must believe that the student must see, and hear, and feel for himself being at the bedside of the sick to build up their own perception and plan clinical sessions for effective learning.

Demonstration and discussion at the bedside is the most preferred area for learning activities. However, designated areas in or around the ward where discussion can occur with or without the patient, models, radiological or other images, Laboratory reports, Specimens of tissue or other biological materials can serve the purpose well. Addition to this may be arrangement for teleconferencing with regional or international centers.

Effective learning and teaching sessions can be arranged by planning well ahead by informing and including the patients, conducting the session in a controlled environment and debriefing after the session 
along with assessment of learning. One key point for success is involvement of all learners in the process.

Teaching residents in a clinical setting is a complex and challenging endeavor. Basic learning principles that applies to clinical learning and teaching are that knowledge is constructed, not accumulated expertise depends on experience with cases, students learn when they are involved, and that Learning is both a personal and a social process. Students and residents learn, and enriched by the extent to which the teaching responds to learning needs and to the extent that it facilitates learning. Clinical teachers might consider a model of instruction in which teaching is enabling, knowledge is understanding, and learning involves not memorization but active construction 5

A five-step model of clinical teaching that utilizes simple, discrete teaching behaviors or "micro skills." has been advocated. The five micro skills are (1) get a commitment, (2) probe for supporting evidence, (3) teach general rules, (4) reinforce what was done right, and (5) correct mistakes. 6 Newer options of teaching and evaluation like Multiple station Clinical teaching Scenario (MCTS) and MiniCx (Minute Clinical Examination ) are now being practiced for effective learning .

New challenges in clinical learning and teaching set up involves introduction of information technology (IT) in health and education and rising number of senior citizens with multisystem involvement posing complex clinical problem demanding time and attention of consultants and terminal care patients who need active medical care. But theses can well be utilized to facilitate and extend our knowledge. IT provides opportunity to collect up to date information and evidences during discussion or any learning session. A networking system with different departments or institutions or resource for teleconferencing will involve learners for effective learning. Senior trainees may be exposed to terminally sick patients for learning experiences in this new frontier of medical management as well as dealing with patients relations at such situations.

Management of educational environment remains a key issue in our setting.. This emerges from unmanageably excess number of patients, many of them are terminally ill. To this is added our social system of family support during sorrow and sickness. A number of different factors are related to overcrowding in our hospitals. Availability of beds and facilities, expertise, financial constrains and lack of confidence are some of them. Extension of health service, provision of treatment facilities and most importantly confidence development through development and ensuring availability of appropriate health man power might bring the patient load to a manageable level. For our hospitals a systematic admission policy, logistic support to patient care, emergency situation might change the scenario and establish an atmosphere of learning for all.

"We must acknowledge again that the most important, indeed, the only, thing we have to offer our students is ourselves. Everything else they can read in a book or discover independently, usually with a better understanding than our efforts can convey." 7

\section{References:}

1. John Spencer. Learning and teaching in the clinical environment; Clinical review BMJ 2003; 326: 591-594.

2. Ende, J. What if Osler were one of us?: Inpatient teaching today J Gen Intern Med. 1997 1; 12(S2): S41-S48.

3. Fitzgerald FT: Bedside teaching. West J Med 1993; 158: 418-420.

4. Tremonti LP, Biddle WB: Teaching behaviors of residents and faculty members. $J$ Med Educ. 1982; 57: 854-859.

5. Hewson MG. Clinical teaching in the ambulatory setting. J Gen Intern Med. 1992; 7: 76-82.

6. Neher JO, Gordon KC, Meyer B, Stevens N. A five-step "microskills" model of clinical teaching. J Am Board Fam Pract. 1992; 5(4): 419-24.

7. Tosteson DC. Learning in Medicine. N Engl J Med. 1979: 301(13): 6904. 